\title{
Achenbach's Syndrome Revisited: The Paroxysmal Finger Hematoma May Have a Genetic Link
}

\author{
Patrick Harnarayan' \\ Michael J Ramdass (D) \\ Shariful Islam (1D) ${ }^{2}$ \\ Vijay Naraynsingh (D) ${ }^{3}$ \\ 'Department of Clinical Surgical Sciences, \\ University of the West Indies, \\ St. Augustine, Trinidad and Tobago; \\ ${ }^{2}$ Department of Surgery, San Fernando \\ General \& Teaching Hospital, San \\ Fernando, Trinidad and Tobago; \\ ${ }^{3}$ Department of Surgery, Medical \\ Associates Hospital, St. Joseph, Trinidad \\ and Tobago
}

Correspondence: Patrick Harnarayan Email patrick_harnarayan@hotmail.com

\begin{abstract}
Achenbach's syndrome describes the sudden occurrence of bruising, pain and swelling of one or more digits of the hand involving the volar aspect of the proximal and middle phalanges. Also known as the paroxysmal finger hematoma, it presents in dramatic fashion, sometimes with a prodrome of tingling, itching or numbness but despite its dramatic presentation, all investigations are normal. Routine blood investigations, as well as coagulation and thrombophilia screens are all negative as are vascular imaging and echocardiography. The diagnosis is solely clinical. Due to the nature of its presentation, almost all patients are referred for an urgent vascular consultation but the condition resolves spontaneously usually within 2-3 days, although the discoloration may persist for longer. Its appearance usually leads clinicians to start anticoagulation in the belief that it may progress but, in fact, it settles as quickly as it appears. Though there are episodic cases which recur years later, it is generally self-resolving with no complications nor residual morbidity. Although the etiology was previously unknown, there is now a recognized genetic link. Genes related to the acute phase reactive proteins and the coagulation and complement cascades appear to be linked to Achenbach's syndrome. This evidence may explain why only certain individuals seem prone to this acutely painful, bruising disorder. We review this interesting disorder and compare patients from the tropical Caribbean region with similar cases from the temperate United Kingdom and discuss whether there are climatic variations in presentations.
\end{abstract}

Keywords: acute pain, finger- bruising, spontaneous-resolution, negative investigations

\section{Plain Language Summary}

This paper highlights patients who present with acutely painful blue-tinged and discoloured fingers but in whom all investigations (blood and imaging) are negative. These appear to be vascular emergencies but resolve on their own, usually with no side effects nor long-term disabilities. Sometimes physicians place patients on anticoagulant (blood-thinning) therapy but the outcome is the same. Though there was no known cause, recent genetic markers have identified certain human genes liked with this disease. Of note, these genes code for the blood clotting pathways, as well as acute phase reacting proteins. This may help to explain the clinical appearance seen and why only certain patients, being genetically susceptible, are affected.

\section{Introduction}

Achenbach's syndrome is an uncommon condition in which patients describe a sudden, painful, and alarming discoloration of one or more fingers of the hand. ${ }^{1}$ Though listed as a rare disease it is seen fairly regularly in the practice of medicine ${ }^{2}$ being more common in women. ${ }^{3}$ Described by the German physician Walter Achenbach in $1958,{ }^{4}$ this disease is dramatic in its presentation but has a rather 
benign course, resolving without treatment within a matter of days. ${ }^{5}$ Initially it appears to be an emergency of traumatic, ischemic, or hematological origin but patients usually deny any history of significant trauma. They may, however, admit to trivial physical contact such as household activities which fails to explain its sudden, painful, and dramatic appearance. There is now sufficient evidence to suggest this disease may have a familial link due to both experimental genetic research and clinical cases within immediate family members.

In order to enhance this review, we present cases of Achenbach's syndrome, (three) from the tropical Caribbean islands of Trinidad and Tobago, and (two) cases from the United Kingdom (UK) for comparison. It has not, to our knowledge, been previously described in the Caribbean region.

\section{Materials}

\section{United Kingdom (UK) Cases}

A 68-year-old male Caucasian patient presented with sudden pain and bruising along the volar aspect of his right ring finger. There was no history of trauma, he was in discomfort then mild pain with some proximal edema. The bruising which was purpuric in nature became less prominent over the next 12 hours. All blood investigations including coagulation and hemophilia screens were normal, whilst a duplex scan (Doppler+ Ultrasound) showed no abnormality of flow, thrombus nor vessel abnormality and an echocardiography was negative for valve vegetation and thrombus formation.

A 48-year-old Caucasian housewife had pain and bruising of the right middle finger with no previous history of trauma. She had a painful, cold, cyanotic finger and it appeared so ischemic that she was investigated further since arterial disease was suspected. A DSA-angiogram was requested but no abnormality was observed. The condition resolved spontaneously although she did receive an intravenous infusion of heparin for about 12 hours. She had no abnormal blood investigations and she was discharged without issue. One year later she was readmitted with similar symptoms but settled on conservative management and there were no further episodes.

\section{Caribbean (Trinidad and Tobago) Cases}

A 67-year-old housewife of Asian East-Indian descent, presented with bruising of the middle and ring fingers with some pain but no swelling. She was admitted for treatment but all blood investigations as well as echocardiography and duplex imaging proved to be negative. She was placed on subcutaneous low molecular weight heparin but her symptoms resolved within 72 hours and she was discharged with no recurrence of symptoms.

A 65-year-old retired male of Asian East-Indian ethnicity presented with discoloration and swelling, with mild discomfort of his ring and middle fingers [Figure 1]. All hematological, imaging (duplex scan) and cardiology investigations which were done, were normal. Though his symptoms resolved within 48 hours he was placed on prophylactic doses of subcutaneous low molecular weight heparin and discharged with no recurrence [Figure 2].

A 30-year-old right-handed brokerage clerk presented with pain and swelling of his left index finger. He smoked for 15 years but gave no history of trauma. He was suspected of having an ischemic episode due to thrombosis possibly due to is prolonged smoking. All blood investigations (including hemoglobin, platelet count, ESR, thrombophilia screen and antinuclear factor) were negative, his Doppler ultrasound (duplex) was normal from the left

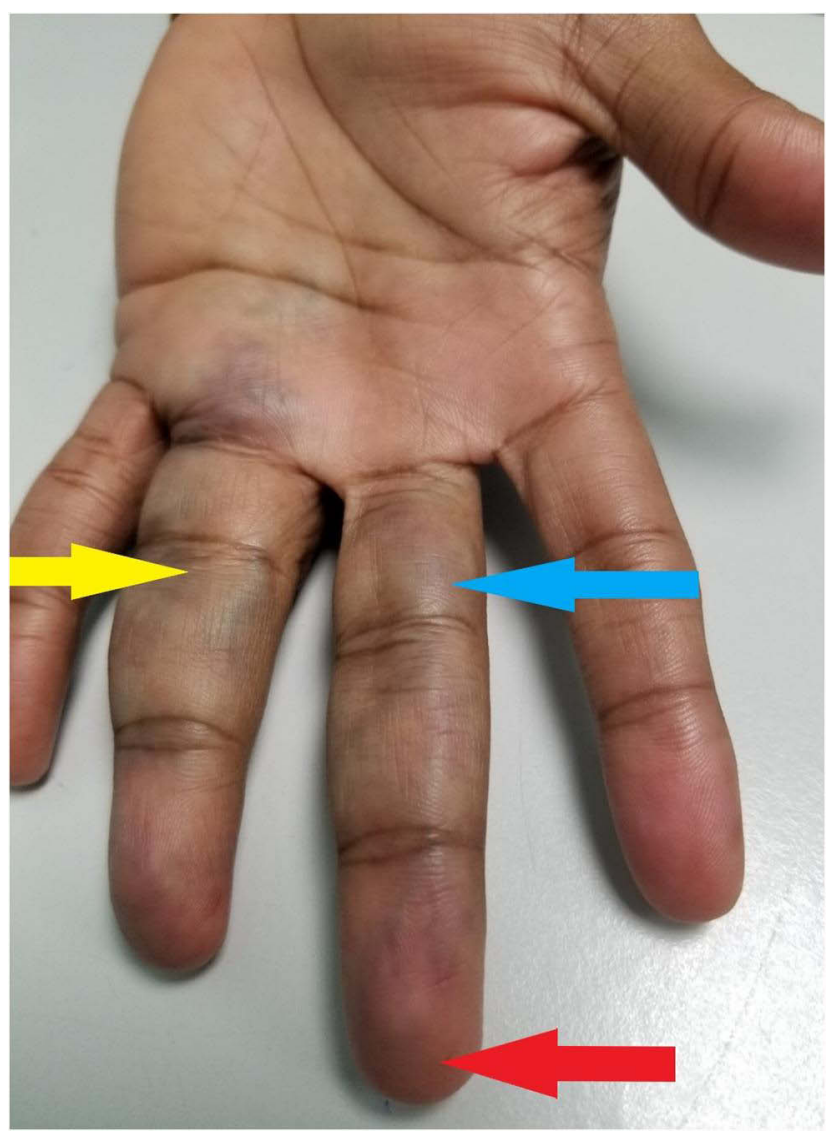

Figure I Bruising of the proximal and middle phalanges of middle finger (blue arrow) and ring finger (yellow arrow) with apical sparing (red arrow). 


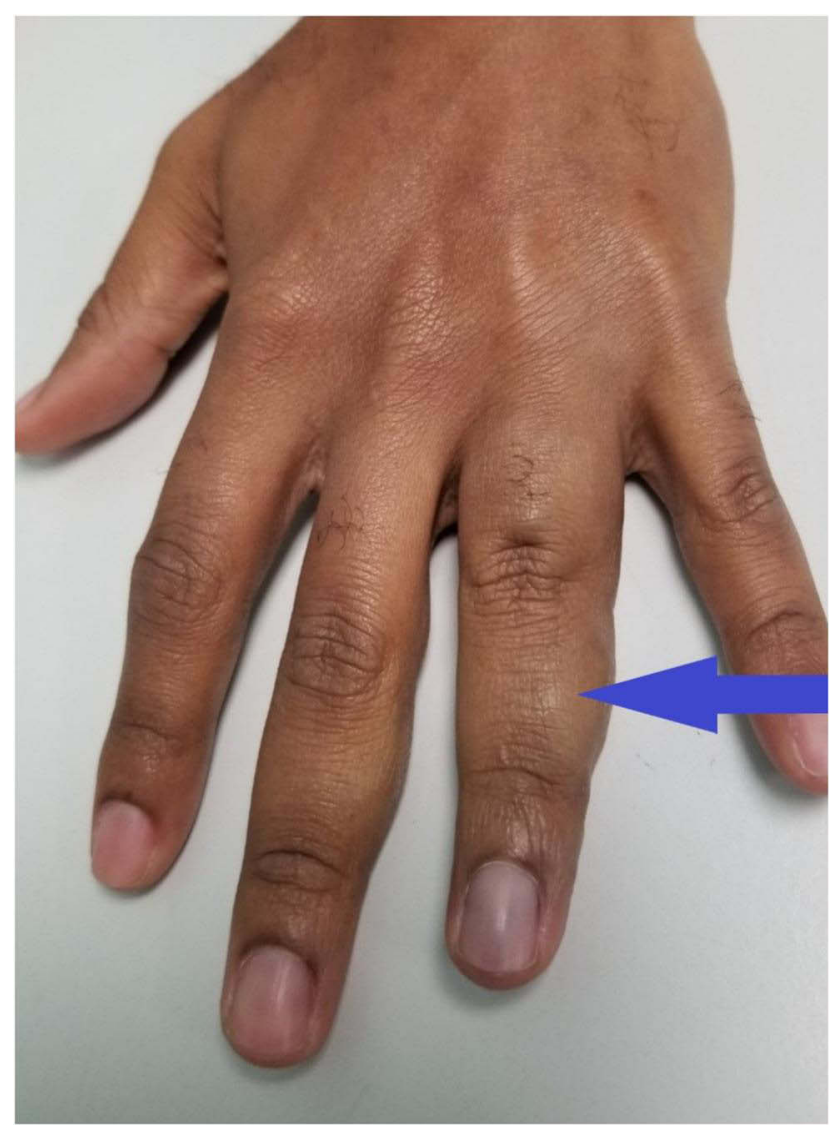

Figure 2 Dorsal view showing edema (purple arrow) of the middle phalanx of the finger.

axillary artery to left palmar arch with no evidence of thromboses nor intimal wall thickening. The peak systolic velocities within the vessels were all within normal range. He was further investigated by way of CT angiogram of left upper limb from left subclavian to the wrist and showed no thromboses nor filling defects, with all visualized vessels appearing normal but there was an incidental small sub-centimeter dilatation seen along the palmar arch. This was thought to be the cause of his appearance but there was no evidence of distal embolization, any filling defect nor thrombosis.

He underwent a punch skin biopsy of the left index finger. This showed hyperkeratosis of the epithelium and multiple ectactic capillaries in the dermal layer as well as some extravasation of red blood cells out of these vessels into the dermis. This suggests some degree of vessel fragility with no evidence of thrombosis [Figures 3 and 4].

Considering these five patients, the first two were seen in Nottingham, UK, the other three in San Fernando, Trinidad and Tobago. They were all generally middle-

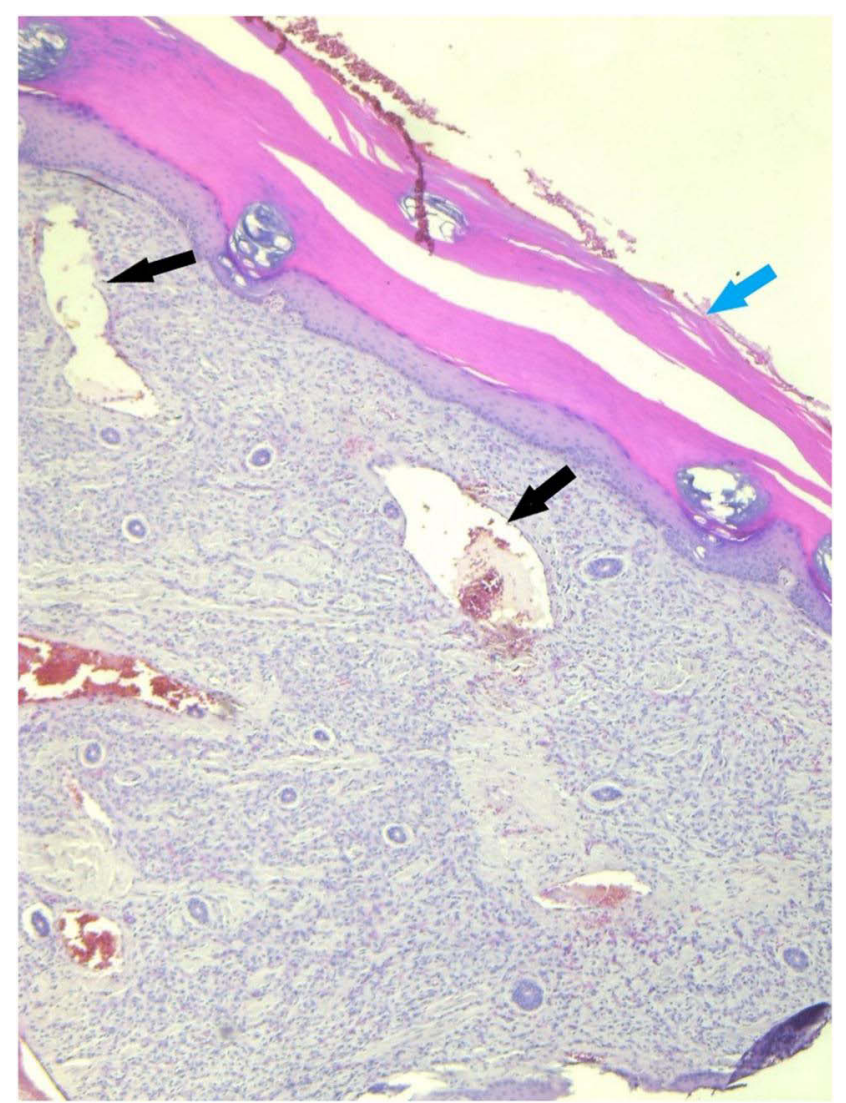

Figure 3 Skin biopsy: Low-power microscopy showing hyperkeratosis of epidermis (blue arrow) and multiple ectactic capillaries in the dermis (black arrows).

aged patients comprising two males and two females with one young (30-year-old) male each having negative investigations and one (48-year-old UK housewife) having a recurrence one year later with no sequelae. There appears to be no clinical variation in these individuals seen in different climatic settings.

The patients in this series have all consented to take part in this study with the full knowledge it is to be published and consent has also been obtained for the photographic images of the two patients to be published.

\section{Discussion}

Achenbach's syndrome is a condition of unknown etiology which presents as a vascular emergency. Patients are admitted with a history similar to an acutely ischemic event with pain and discoloration of the digits of one hand. ${ }^{1}$ Named after the German internist Walter Achenbach in $1958,{ }^{4}$ this disease is acute in its presentation but resolves without treatment within a time-frame of between 2 and 14 days. ${ }^{3}$ There is a strong female propensity with middle-age predominance. ${ }^{5}$ It was aptly 


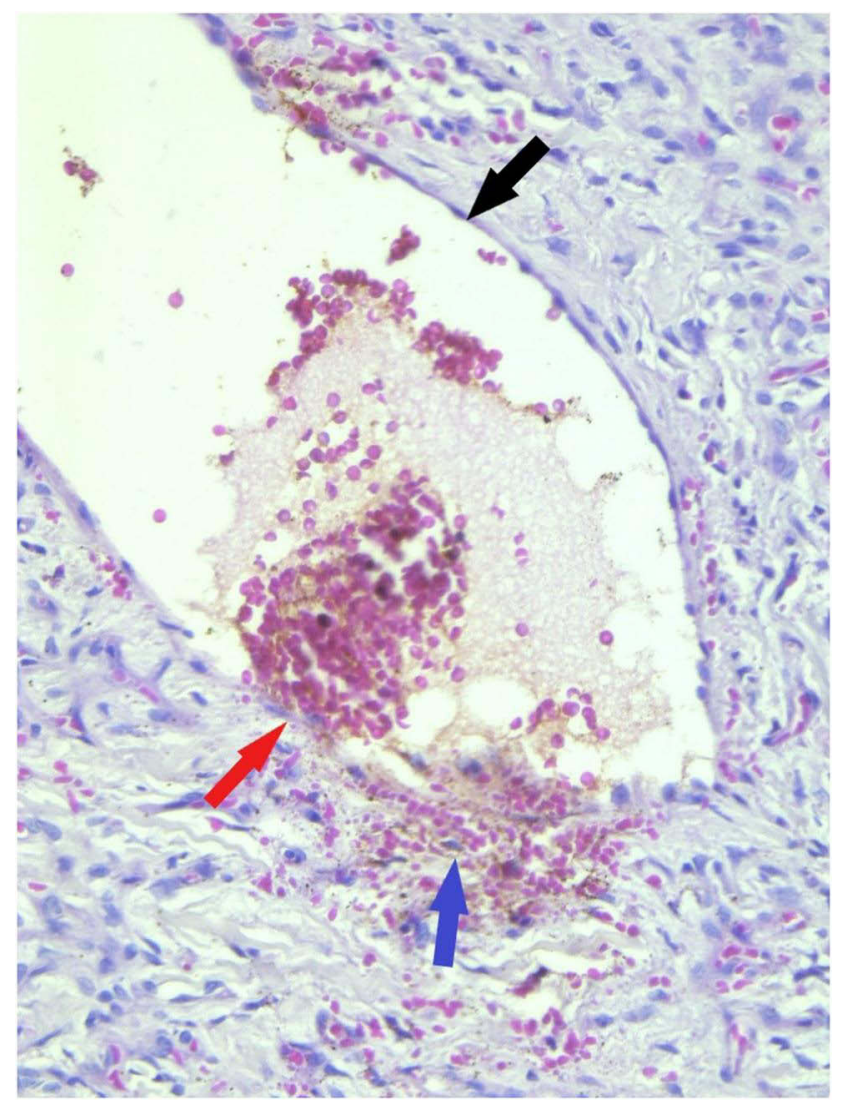

Figure 4 Skin biopsy: High power microscopic magnification showing thin-walled ectactic vessel (black arrow), point of extravasation (red arrow) and red blood cells in the dermis (purple arrow).

described as finger apoplexy or paroxysmal hematoma of the hand (Singer, 1962) ${ }^{6}$ and then the paroxysmal finger hematoma (Stieler, 1990). ${ }^{7}$ In the UK it was first reported by dermatologists (Layton and Cotterill, 1992) who described it as a spontaneously induced hematoma. ${ }^{8}$ Recent evidence (2021) suggests there may now be a familial tendency since it has been reported in two generations of the same family.

It usually appears to be unilateral and affects the volar aspect of the proximal, ${ }^{9}$ middle and sometimes distal phalanges ${ }^{10}$ with terminal sparing. ${ }^{11}$ The middle and ring fingers are the most commonly affected but the little finger, index ${ }^{10}$ and thumb ${ }^{12}$ may be involved either singly or in combination. Added features may include paresthesia, cyanosis, swelling, pruritus, coldness as well as difficulty in moving the joints. ${ }^{13}$ The original description included a hematoma of the finger-pad with concomitant edema. $^{6}$

There may be prodromal symptoms such as pain, tingling and itching before bleeding and bruising begin. ${ }^{12}$ Pain (or ache) in the finger is followed by blue discoloration and can occur from a few minutes to hours before the colour changes occur. ${ }^{9}$ There is no history of trauma and it usually resolves in 4-7 days with no residual effect. $^{9,14}$ Though frequently described as being recurrent, ${ }^{12}$ this is not a consistent finding, but some patients do report repeat episodes every 2-3 months after minor trauma such as doing household activities. ${ }^{12}$ The clinical findings of our patients in two different countries were found to be the same and in general, as described in other series [Table 1].

Though cases are self-resolving, the signs are dramatic and alarming to most patients and they are referred to vascular surgeons, suspecting a vascular calamity is about to occur. ${ }^{1}$ In Achenbach's syndrome many physical examinations including Allen's test, to check the dominant vessel supply to the hand, and the Ankle-Brachial Index (ABI) comparing upper and lower limb blood pressures, are done, but are both normal. Radial and ulna pulses, finger capillary refill and pulse oximetry also show no abnormalities and systemic symptoms and signs seen in the collagen vascular and related disorders are absent. ${ }^{2}$ All routine blood investigations, coagulation and thrombophilia screens also tend be within normal limits. ${ }^{14,15}$

Imaging, in the form of duplex scanning and angiography are sometimes performed (as in our cases) but no stenoses, occlusion, thromboses nor evidence of embolism are ever displayed. ${ }^{12}$ Echocardiography, 24-hour electrocardiograms and even capillaroscopy performed by specialized units are usually negative. ${ }^{14-16}$ Once systemic signs such as fever, hypertension, pulse deficit and tissue necrosis are absent, the diagnosis is made clinically ${ }^{13}$ [Table 1].

In our series, all blood investigations including thrombophilia screen, erythrocyte sedimentation ratio (ESR) and rheumatoid screen were normal in all patients [Table 2]. The imaging investigations were within normal limits, aside from an incidental finding in the final case, in which aneurysmal dilatation of the proximal palmar arch $(<0.8 \mathrm{~cm})$ was noted. This was initially thought to be the cause of the colour changes but there were no distal changes, either occlusions, filling defects, nor evidence of thrombosis.

Since the diagnosis is based on clinical findings as investigations are completely normal, ${ }^{12}$ clinicians must exclude other causes such as Raynaud's phenomenon, thoracic outlet compression syndrome (TOCS), polycythemia, ${ }^{15}$ and exclude the use of drugs such as Ergot alkaloids (used in migraine headaches). Treatment 
Table I Achenbach's Syndrome: Signs, Symptoms, Features, Options and Outcomes

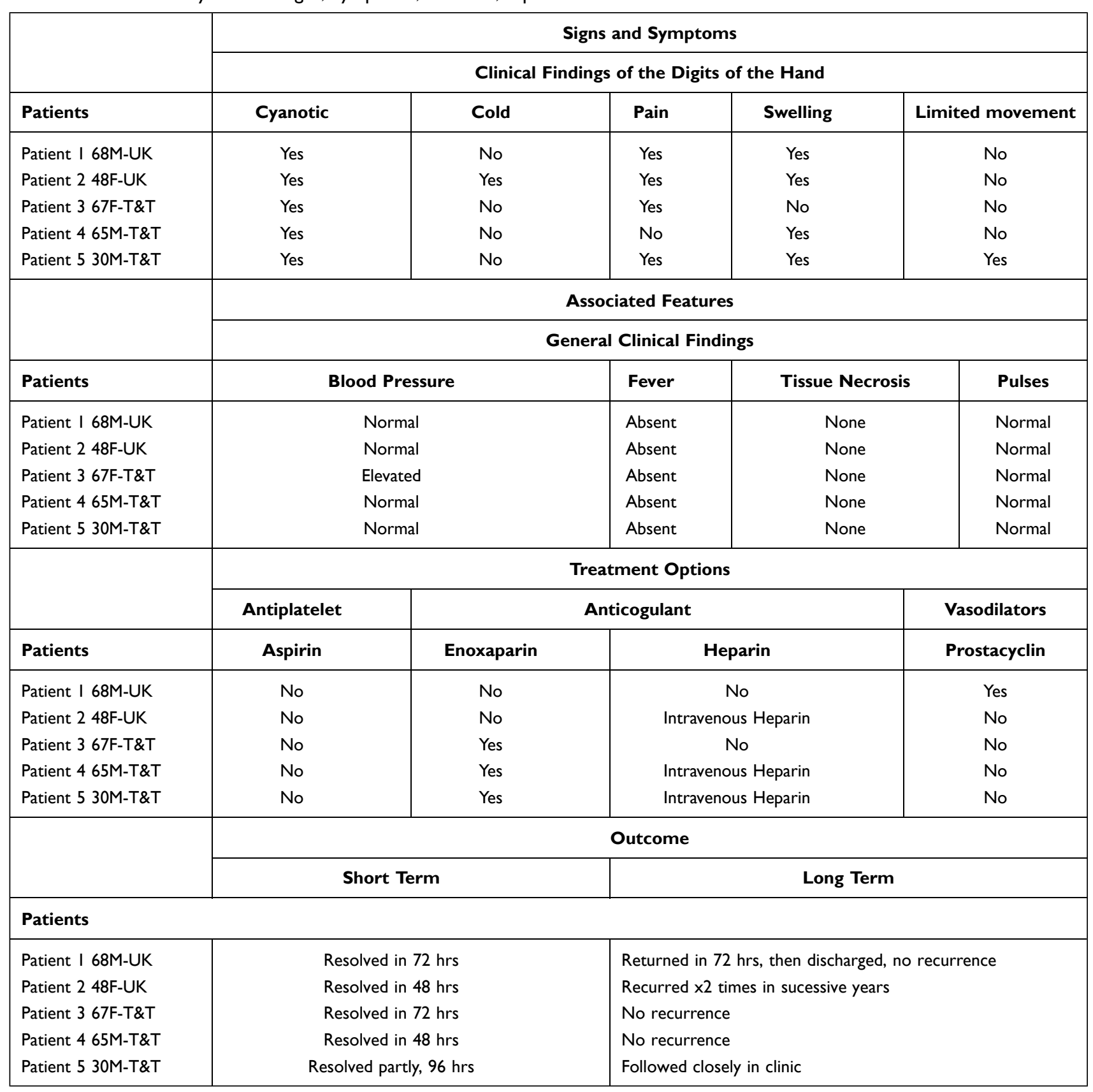

involves reassuring the patient, since the anxiety produced by the pain and the disturbing appearance is usually substantial.

One of the only investigations that provides beneficial information is a punch skin biopsy. The constant histological finding here is the presence of red blood cells in the dermis (and sometimes beyond) with normal blood vessels. This is equivalent to dermal hemorrhage with intact vessel walls, ${ }^{13}$ but sometimes hyperkeratosis and parakeratosis may also be present. ${ }^{16}$ So at the histological level, a degree of capillary fragility with extravasation of red blood cells into the dermis is seen (as in our patient \#5). Our first four patients did not have skin biopsies since this was not in practice at that time, the evidence for its use having arisen only within the last two years (Watanabe, 2019; Ashrafzadeh 2020). Only the most recent case (case \#5, 2021) has had the benefit of this investigation. This confirmed the presence of 
Table 2 Patients, Investigations and Results

\begin{tabular}{|c|c|c|c|c|c|c|}
\hline \multicolumn{7}{|c|}{ Achenbach's Syndrome } \\
\hline \multicolumn{2}{|l|}{ Patients } & $\mathbf{I}$ & 2 & 3 & 4 & 5 \\
\hline \multicolumn{2}{|l|}{ Age, Gender } & $68 M$ & $48 \mathrm{~F}$ & $67 F$ & $65 M$ & $30 M$ \\
\hline \multicolumn{2}{|l|}{ Investigation } & \multicolumn{5}{|c|}{ Investigation Outcome } \\
\hline \multirow[t]{2}{*}{ Full Blood Count } & Requested & Yes & Yes & Yes & Yes & Yes \\
\hline & Normal & Yes & Yes & Yes & Yes & Yes \\
\hline \multirow[t]{2}{*}{ Thrombophilia screen } & Requested & Yes & Yes & Yes & Yes & Yes \\
\hline & Normal & Yes & Yes & Yes & Yes & Yes \\
\hline \multirow[t]{2}{*}{ ESR } & Requested & Yes & No & Yes & No & Yes \\
\hline & Normal & Yes & $\mathrm{N} / \mathrm{A}$ & Yes & N/A & Yes \\
\hline \multirow[t]{2}{*}{ ECG, ECHO } & Requested & Yes & Yes & Yes & Yes & Yes \\
\hline & Normal & Yes & Yes & Yes & Yes & Yes \\
\hline \multirow[t]{2}{*}{ PULSES } & Checked & Yes & Yes & Yes & Yes & Yes \\
\hline & Normal & Yes & Yes & Yes & Yes & Yes \\
\hline \multirow[t]{2}{*}{ Hand-Held Doppler } & Done & Yes & Yes & Yes & Yes & Yes \\
\hline & Normal & Yes & Yes & Yes & Yes & Yes \\
\hline \multirow[t]{2}{*}{ Duplex (USS) } & Done & Yes & No & Yes & Yes & Yes \\
\hline & Normal & Yes & N/A & Yes & Yes & Yes \\
\hline \multirow[t]{2}{*}{ Angiography } & Done & No & Yes & No & No & Yes \\
\hline & Normal & $\mathrm{N} / \mathrm{A}$ & Yes & $\mathrm{N} / \mathrm{A}$ & $\mathrm{N} / \mathrm{A}$ & No* \\
\hline \multirow[t]{2}{*}{ Punch Skin Biopsy } & Done & No & No & No & No & Yes \\
\hline & Normal & $N / A$ & $\mathrm{~N} / \mathrm{A}$ & $N / A$ & $N / A$ & No** \\
\hline \multirow[t]{5}{*}{ Known Diseases } & Raynaud's & No & No & No & No & No \\
\hline & Rheumatoid Arthritis & No & No & No & No & No \\
\hline & Thoracic Outlet Syn. & No & No & No & No & No \\
\hline & Atrial fibrillation & No & No & No & No & No \\
\hline & Cardiac Disease & No & No & No & No & No \\
\hline \multirow[t]{3}{*}{ Drugs } & NSAIDS & No & No & No & No & No \\
\hline & Ergot Alkaloids & No & No & No & No & No \\
\hline & Aspirin & No & No & No & No & No \\
\hline \multirow[t]{2}{*}{ History of trauma } & Minor Trauma & No & No & No & No & No \\
\hline & Major Trauma & No & No & No & No & No \\
\hline
\end{tabular}

Notes: No* - Angiogram showed normal filling, no thromboses, no stenoses but an incidental finding of an aneurysmal dilatation along the palmar arch of the first metacarpal vessel. No** - Punch biopsy showed hyperkeratosis, ectactic vessels with extravasation of red cells which are typical findings in this syndrome.

Abbreviations: N/A, Non Applicable; USS, Ultrasound scan; Syn., syndrome; NSAIDS, Non steroidal anti-inflammatory drugs.

hyperkeratosis of the epidermis and widespread ectactic capillaries within the dermis [Figure 3], which is one of the hallmark features of Achenbach's syndrome. In addition to this, another feature is the extravasation of red blood cells presumably due to fragility of these ectactic vessels into the layer of the dermis [Figure 4]. This can be diagnosed by capillaroscopy. ${ }^{17}$
This fragility linked with either minor trauma or spontaneity causing extravasation of red blood cells is seen in our fifth patient and accounts for the colour change and pain and the resolution of the symptoms. However, there is no evidence of clumping of red cells nor increased fibrin deposition to suggest thrombosis within or outside the vessels. 
In terms of its etiology, recent evidence (June, 2021) has revealed a familial link, with three cases appearing within the same family in two successive generations. ${ }^{18}$ The presence of multiple cases within one family indicates that a genetic link may exist and though this is the first such report, correlation needs to be made with experimental (genetic) evidence to confirm this link.

Research evidence has shown that a relationship has already been established with a gene now thought to have an association with Achenbach syndrome. ${ }^{19}$ Though it is linked with thrombosis and not capillary fragility, the F3 gene ${ }^{19}$ has been found to be associated with it through the pathways of fibrin clot formation by way of the complement and coagulation cascades. The F3 gene codes for the Coagulation factor III as well as Tissue Factor although the strength of the relationship is weak experimentally (Confidence level 1 out of 5).

The F2 gene (Coagulation factor II, Thrombin) and gene for CRP (C-Reactive Protein) have also been linked to this syndrome. The biological processes involved are blood coagulation (F3/F2 genes), hemostasis (F3/F2 genes) as well as the acute phase response (F2/CRP genes) and at the molecular level, the functions include serine-type endopeptidase activity (F3 and F2 genes). ${ }^{19}$

There are many other diseases linked with Achenbach syndrome due to the experimental relationship with the F3 and CRP genes such as the subclavian steal syndrome, critical illness polyneuropathy, autoimmune disease of the blood and angina pectoris. Specific information is not yet available, so although the F3 and F2 genes are related to thrombosis, the exact nature of the relationship has not been made clear and the association is still at a low level. In addition, the clinical nature of Achenbach syndrome appears to be one of capillary fragility with red cell extravasation and not thrombosis. This is borne out in the histological specimens taken at biopsy which confirm these findings [Figure 3]. Indeed, vascular imaging never reveals any abnormalities such as thromboses, filling defects, nor intimal thickening but good opacification of the subclavian, axillary, brachial, and forearm arteries and terminal vessels with normal peak systolic velocities, as in our series [Table 2].

These experimental findings and the presence of multiple family members diagnosed with Achenbach's syndrome, ${ }^{18}$ are supporting evidence for a genetic basis of this disease, even if this is not strong at present. ${ }^{20}$

\section{Conclusion}

Achenbach's syndrome is a disease in which the dramatic, painful discoloration of one or more fingers is self-resolving involving negative blood and imaging investigations, but has no known etiology. It is sometimes recurrent but has no sequelae and is not associated with morbidity nor mortality. It is described here in a Caribbean population where the cases are comparable clinically with those seen in temperate climates. Recent evidence suggests that a genetic component may exist and the F3 gene together with the F2 and CRP genes have been considered to be possible links. With further research, it will be possible to uncover whether there is a strengthening of this genetic relationship.

\section{Consent and Ethical Approval}

Informed consent was obtained from all the patients involved in this series for the case details and images to be published. Institutional Review was sought from the San Fernando General \& Teaching Hospitals/South-West Regional Health Authority's Bioethics Committee but not required for this review article. This study was conducted in accordance with the Declaration of Helsinki.

\section{Author Contributions}

All authors made a significant contribution to the work reported, whether that is in the conception, study design, execution, acquisition of data, analysis and interpretation, or in all these areas; took part in drafting, revising or critically reviewing the article; gave final approval of the version to be published; have agreed on the journal to which the article has been submitted; and agree to be accountable for all aspects of the work.

\section{Funding}

The authors received no funding for this article.

\section{Disclosure}

The authors report no conflicts of interest in publishing this article.

\section{References}

1. Ribeiro F, Aveiro M, Leal M, Valente T, Jesus G. An acute blue finger: a case of Achenbach's Syndrome. Eur J Case Rep Intern Med. 2019;6 (9):001231. doi:10.12890/2019_001231

2. Takeuchi H, Uchida HA, Okuyama Y, Wada J. Acute idiopathic blue fingers: a young man with Achenbach's syndrome. BMJ Case Rep. 2016;2016:10.1136/bcr-2016-214491. doi:10.1136/bcr-2016-214491 
3. Kordzadeh A, Caine PL, Jonas A, et al. Is Achenbach's syndrome a surgical emergency? A systematic review. Eur J Trauma Emerg Surg. 2016;42:439-443. doi:10.1007/s00068-015-0610-0

4. Achenbach W. The paroxysmale hand-hematoma. Medizinische. 1958;52(27):2138-2140.

5. Ahmed Z, Elmallah A, Elnagar M, Dowdall J, Barry M, Sheehan SJ. Painful blue Finger-Achenbach's syndrome: two case reports. EJVES Short Rep. 2018;40:1-2. doi:10.1016/j.ejvssr.2018.05.008

6. Singer R. On the symptoms and diagnosis of finger apoplexy (paroxysmal hematoma of the hand). Wien Klin Wochenschr. 1962;74:741-743.

7. Stieler W, Heinze-Werlitz C. Paroxysmales Fingerhämatom (Achenbach-Syndrom) [Paroxysmal finger hematoma (Achenbach syndrome)]. Hautarzt. 1990;41(5):270-271. [German].

8. Layton AM, Cotterill JA. A case of Achenbach's sydrome. Clinc Exp Dermatol. 1993;18(1):60. doi:10.1111/j.1365-2230.1993.tb00970.x

9. Godoy A, Tabares AH. Achenbach syndrome (paroxysmal finger hematoma). Vasc Med. 2019;24(4):361-366. doi:10.1177/ 1358863X19849627

10. Ada F, Kasimzade F. Analysis of 24 patients with Achenbach's syndrome. World J Clin Cases. 2019;7(10):1103-1110. doi:10.12998/wjcc.v7.i10.1103

11. Yie K. Achenbach syndrome: a benign painful blue finger with tip sparing. Vasc Specialist Int. 2019;35(4):251-253. doi:10.5758/ vsi.2019.35.4.251

12. Mishra P, Jain A, Sen S, Majumdar B. Recurrent bleeding and bruising over little finger: a diagnostic conundrum! Indian J Dermatol. 2015;60(6):632-633. doi:10.4103/0019-5154.169155
13. Ashrafzadeh S, Xue Y, Horn TD, Korman JB. The case of a painful blue thumb. JAAD Case Rep. 2020;6(10):1053-1055. doi:10.1016/j. jdcr.2020.06.045

14. Khaira HS, Rittoo D, Vohra RK, Smith SR. The non-ischaemic blue finger. Ann R Coll Surg Engl. 2001;83(3):154-157. PMID: 11432130; PMCID: PMC2503579.

15. Cowen R, Richards T, Dharmadasa A, Handa A, Perkins JM. The acute blue finger: management and outcome. Ann R Coll Surg Engl. 2008;90(7):557-560. doi:10.1308/003588408X318237

16. Watanabe S, Hashiguchi N, Kobayashi H. Paroxysmal bruising in the finger -Achenbach's syndrome. JMA J. 2019;2(1):89-90.

17. Frerix M, Richter K, Müller-Ladner U, Hermann W. Achenbach's syndrome (paroxysmal finger hematoma) with capillaroscopic evidence of microhemorrhages. Arthritis Rheumatol. 2015;67(4):1073. doi:10.1002/art.39003

18. Helm RH. Achenbach syndrome: a report of three familial cases. J Hand Surg Eur Vol. 2021:175319342110245. PMID: 34139905. doi:10.1177/17531934211024567

19. Stelzer G, Rosen R, Plaschkes I, et al. The genecards suite: from gene data mining to disease genome sequence analysis. Curr Protoc Bioinform. 2016;54:1.30.1-1.30.33. doi:10.1002/cpbi.5

20. Rappaport N, Twik M, Plaschkes I, et al. MalaCards: an amalgamated human disease compendium with diverse clinical and genetic annotation and structured search. Nucleic Acids Res. 2017;45(D1):D877D887. doi:10.1093/nar/gkw1012
Vascular Health and Risk Management

\section{Publish your work in this journal}

Vascular Health and Risk Management is an international, peerreviewed journal of therapeutics and risk management, focusing on concise rapid reporting of clinical studies on the processes involved in the maintenance of vascular health; the monitoring, prevention and treatment of vascular disease and its sequelae; and the involvement

\section{Dovepress}

of metabolic disorders, particularly diabetes. This journal is indexed on PubMed Central and MedLine. The manuscript management system is completely online and includes a very quick and fair peerreview system, which is all easy to use. Visit http://www.dovepress. com/testimonials.php to read real quotes from published authors. 